\title{
An Unusual Complication of a Usually 'Innocent' Parasitic Worm
}

\author{
G. Kouklakis ${ }^{a} \quad$ A. Mpoumponaris ${ }^{a} \quad$ J. Moschos $^{a} \quad$ A. Koulaouzidis ${ }^{b}$ S. Bhat ${ }^{a}$ \\ E. Efremidou ${ }^{\text {a }}$ N. Lyratzopoulos ${ }^{\text {a }}$
}

a Medical School, Democritus University of Thrace, Alexandroupolis, Greece; and 'barrington Hospital, Cheshire, UK

A 35-year-old man presented with fever, rigors, watery diarrhea and tenesmus associated with vague abdominal pain. There was no personal or family history of bowel disease.

On examination he had tenderness in the left iliac fossa, and digital rectal examination revealed a palpable mass at $7 \mathrm{~cm}$ from the anal verge. His white cell count (WCC) was $13.3 \times 10^{9} / \mu \mathrm{l}$ with associated neutrophilia and eosinophilia. Microscopic examination of consecutive stool samples demonstrated the presence of Enterobius vermicularis (pinworm).

A subsequent colonoscopy showed many pinworms throughout the large intestine. The opening of an abscess was seen in the lower rectum (fig. 1). Unexpectedly, a pin- worm was captured while entering the abscess cavity (fig. 2). The patient was treated with oral metronidazole and mebendazole. He quickly recovered and a repeat colonoscopy 20 days later was entirely normal.

E. vermicularis, the most common intestinal parasite in the developed world, is usually of little clinical significance. It is acquired by the feco-oral route. Ingested eggs hatch in the duodenum. The majority of infested individuals experience pruritus ani and disturbed sleep [1]. However, ectopic pinworm migration can lead to a number of unusual clinical presentations. Pelvic pain, eosinophilic ileocolitis $[2,3]$, perineal nodules [4], perianal and ischioanal abscesses as well as urinary tract infections [5] have been described in association with pinworm infection.

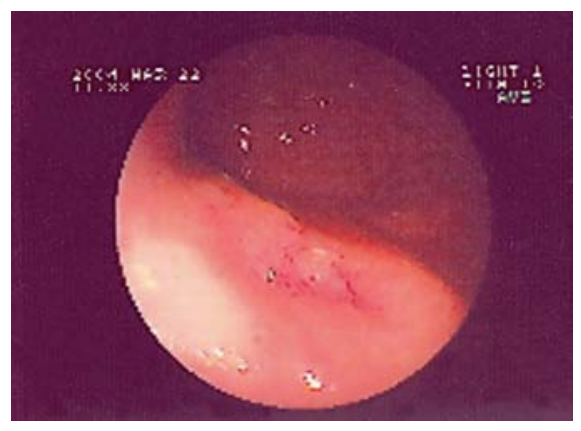

Fig. 1. Opening of an abscess in the rectum.
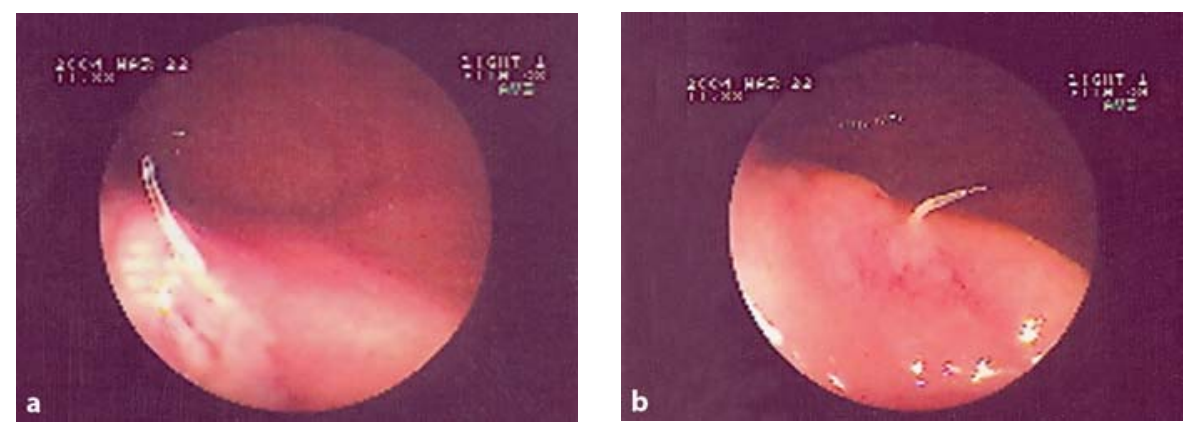

Fig. 2. A pinworm captured whilst entering the abscess cavity.

\section{KARGER}

Fax +41613061234 E-Mail karger@karger.ch www.karger.com 
References terobiasis: a histopathological study of 259 patients. Ann Trop Med Parasitol 1991;85: 625-635.

2 Liu LX, Chi J, Upton MP, et al: Eosinophilic colitis associated with larvae of the pinworm Enterobius vermicularis. Lancet 1995;346: 410-412.

3 Macedo T, MacCarty RL: Eosinophilic ileocolitis secondary to Enterobius vermicularis: case report. Abdom Imaging 2000;25:530532.
4 Kumar N, Sharma P, Sachdera R, et al: Perineal nodule due to enterobiasis: an aspiration cytologic diagnosis. Diagn Cytopathol 2003;28:58-60.

5 Erhan Y, Zekioglu O, Ozdemir N, et al: Unilateral salpingitis due to Enterobius vermicularis. Int J Gynecol Pathol 2000;19:188-189. 